\title{
La infancia errante: ¿Un problema sin solución? El centro y sureste bonaerense entre las décadas de 1890 y 1910
}

\section{Childhood wandering: Problem without solution? The central and South East Buenos Aires province between the 1890 s and 1910}

\author{
Yolanda de PazTrueba \\ Consejo Nacional de Investigaciones Científicas y Técnicas \\ Instituto de Estudios Histórico Sociales \\ Instituto de Geografía, Historia y Ciencias Sociales \\ Universidad Nacional del Centro de la Provincia de Buenos Aires \\ (Argentina) \\ yolidepaz@gmail.com
}

\section{Resumen}

El problema de la mendicidad infantil y la vagancia callejera se tornó insoslayable en Azul y Tandil, especialmente a partir del nuevo siglo y ante el aumento de población que experimentaron estos espacios. El objetivo de este trabajo es analizar desde un lugar del interior de la provincia de Buenos Aires los resultados que arrojaron los esfuerzos realizados por aquellos sectores benefactores que encararon proyectos de protección de la infancia. La prensa local y las fuentes de las instituciones que fundaron y sostuvieron asilos de huérfanos en Azul y Tandil, serán las puertas de entrada para pensar posibles respuestas. Cómo fue percibido el problema de la infancia por la prensa que lo transmitió en las primeras décadas del siglo XX y qué soluciones fueron puestas en práctica atendiendo a sus diferencias en relación a las niñas y niños, serán el inicio del recorrido propuesto en las páginas que siguen.

Palabras clave: Infancia - Mendicidad - Asilos - Niños - Niñas - Prensa 


\begin{abstract}
The problem of child begging and vagrancy became essential in Azul and Tandil, especially, in the beginning of the new century. The aim of this paper is to analyze the results yielded by the efforts of benefactors who tried to achieve child protection in some towns of the province of Buenos Aires. Local media and documentary sources of institutions that had founded and maintained orphanages in Azul and Tandil, will be our starting point for thinking possible answers. We are interested in the way that the press has perceived the problem of childhood in the early decades of the twentieth century and in the different solutions that were implemented in relation to both boys and girls.
\end{abstract}

Key Words: Childhood - Begging - Orphanages - Boys - Girls - Press

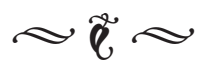

\section{Introducción}

El objetivo de este trabajo es centrarme en dos localidades del interior de la provincia de Buenos Aires, para analizar las políticas implementadas para la protección de la infancia y los resultados que arrojaron los esfuerzos realizados por aquellos sectores que encararon esos proyectos. ${ }^{1} \mathrm{Al}$ persistir el vagabundeo y la mendicidad infantil cuando hacía varios años que existían allí asilos que debían cobijarlos, la pregunta que atraviesa este trabajo es si fallaron

1. Se trata de Azul y Tandil, dos localidades del centro y sureste de la provincia de Buenos Aires fundadas en las primeras décadas del siglo diecinueve y que, sobre el final del mismo, atravesaron por un vertiginoso proceso de desarrollo y modernización económica y diversificación social. En el cambio de siglo dejaron atrás, poco a poco, su carácter de pueblos de campaña (centros de población de reducidas dimensiones con una extensa zona rural circundante), e hicieron su transición a la condición de pequeñas ciudades. las estrategias de protección implementadas, o el problema de la infancia era irresoluble. Sostengo que antes que hablar de fracaso es más factible pensar que la modernización y el consecuente aumento de la urbanización de estos espacios, hicieron que las capacidades asistenciales privadas se vieran avasalladas.

Pretendo dar cuenta de esas soluciones y sus resultados, desde un espacio donde fueron protagonistas las asociaciones privadas de corte católico con fuerte presencia femenina. En Azul y Tandil, fueron casi exclusivamente los sectores privados los que generaron, gestionaron y sostuvieron las iniciativas destinadas a la atención de la infancia. La escala local adoptada no es necesaria solo para agregar información o complejizar la ya existente sobre la infancia en otros espacios de mayor magnitud. Adquiere otra relevancia si tenemos en cuenta que durante el período analizado, las únicas estrategias desplegadas en función de atender a los problemas que la niñez entrañaba, fueron las privadas. A excepción de algún subsidio esporádico, los gobiernos 
provincial y nacional no tuvieron intervención en los pueblos estudiados, y fueron solo los actores privados y los gobiernos locales los que contribuyeron a paliar las problemáticas de la infancia. ${ }^{2}$

Si bien en diversos trabajos previos he avanzado en una dirección que ha permitido observar desde una perspectiva de género las estrategias desplegadas en estos espacios de la provincia de Buenos Aires, el presente artículo encarna un intento de completar dicha mirada con el abordaje de las acciones de una comisión católica en pro de los niños de sexo masculino, que complementó las acciones por las niñas en la ciudad de Azul.

La prensa local y las fuentes de las instituciones que fundaron $y$ sostuvieron asilos de huérfanos en Azul y Tandil, serán las puertas de entrada desde las cuales busco asomarme a estas cuestiones y brindar algunas

2. En el espacio abordado no existieron iniciativas estatales de consideración como en la ciudad de Buenos Aires. Como señala Juan Suriano allí, si bien para las autoridades no fue prioritario la creación de nuevas instituciones bajo égida estatal, la Sociedad de Beneficencia y el Patronato de la Infancia, cuyo principal proveedor de recursos era el Estado, encarnaron la estructura preventiva y organizativa como parte de una estrategia estatal. Ver SURIANO, Juan, "El trabajo infantil”, en TORRADO, Susana (compiladora) Población y bienestar en la Argentina del primero al segundo Centenario. Una historia social del siglo XX, T. II, Edhasa, Buenos Aires, 2007, pp. 353-382. Claro que no podemos desconocer que en Buenos Aires la participación privada fue de importancia y la intervención del Estado fue incipiente y estuvo sujeta a vaivenes. Sobre los avatares por los que atravesaron los diferentes proyectos estatales de intervención sobre la infancia, sus avances, retrocesos $y$ las dificultades que encontraron para consolidarse ver: AVERSA, María Marta, "Infancia abandonada y delincuente. De la tutela al patronato público (19101931)", en LVOVICH, Daniel y SURIANO, Juan (editores) Las politicas sociales en perspectiva histórica. Argentina, 1870-1952, Prometeo - Universidad Nacional de General Sarmiento, Buenos Aires, 2006, pp. 89-108. pistas para pensar posibles respuestas. ${ }^{3}$ Cómo fue percibido el problema de la infancia por la prensa que lo transmitió en las primeras décadas del XX y qué soluciones fueron puestas en práctica por las instituciones mencionadas, marcarán el recorrido propuesto en las páginas que siguen.

En definitiva se trata de analizar las distintas nociones, percepciones y acciones sobre la infancia así como sus resultados, en un contexto de modernización y crecimiento que hizo más visible un viejo dilema: el de la infancia errante y vagabunda.

Los hijos de los trabajadores estaban en la mira de aquellos prestos a plantear la cuestión de los menores de edad que pasaban gran parte de su día en la calle, en términos de problema social. En tanto que la familia y la escuela se reforzaron como dos pilares fundamentales desde los cuales formar a los ciudadanos y trabajadores de la nueva nación, los desajustes a este patrón generó un sentido de peligrosidad que puso a los niños y niñas de las clases trabajadoras en el centro de la escena. ${ }^{4}$

3. Se analizan El Orden, El Imparcial, El Ciudadano, El Comercial, La Democracia, El Pueblo, El Eco de Tandil y los libros de actas de las Sociedades Damas de Caridad de Azul y Tandil y de la Pía Unión de San Antonio de Azul.

4. En el periodo analizado y en particular a partir de la sanción de las leyes de educación (la Ley provincial de 1875 con injerencia en la provincia de Buenos Aires y la 1420 con jurisdicción en la Capital Federal y los Territorios Nacionales), se afianzó la separación entre las categorías menor y niño. Menor, se asociaba a aquellos potenciales delincuentes, que no asistían a la escuela, carecían de familia o si la tenían no les brindaba la contención y educación necesaria y se ocupaban de oficios callejeros. Niño en cambio, era aquel contenido en el ámbito escolar y familiar, aunque no quedaban fuera los que trabajaban pero siempre sometidos a una autoridad adulta. Al respecto ver ZAPIOLA, Carolina, La invención del menor: representaciones, discursos y politicas de menores en la ciudad de Buenos Aires, 1882-1921, Tesis de Maestría, UNSAM, Buenos Aires, 2007 y ZAPIOLA, Carolina, Un lugar para los menores. Patronato estatal e 
Así, decía El Orden de la ciudad de Azul en 1914 que “... lo complejo de la vida para las madres que trabajan y que tienen un crecido número de criaturas obliga, casi, a descuidarlos, a tal punto que los niños cuan pajarillos en libertad buscan ansiosamente la calle y su atmósfera para sus juegos...”. Si bien mantuvo un discurso condescendiente con esas madres que no disponían, decía, de juguetes para ofrecerles de modo que "...hagan más atractivo el patio que la algarabía de la calle...”, no por eso dejó de ser crítico contra los progenitores que si “...tienen carácter y se ocupan de su hogar que de otras cosas mundanas no le faltan medios ni recursos de didáctica para hacer que sus hijos pasen el mayor tiempo en su casa...". Este comentario probablemente no era justo con la realidad de la mayoría de estas familias que, ante la necesidad de sustentar su hogar, no contaban con la posibilidad de ejercer un mayor control sobre las actividades de sus hijos durante su larga jornada laboral. Sin embargo, el tono crítico hacia ciertas costumbres y comportamientos de las familias trabajadoras y sus hijos, especialmente la presencia de éstos en las calles, fue parte de un discurso compartido por sectores gobernantes, intelectuales, miembros de sociedades de beneficencia, profesionales asociados al área de la niñez (como médicos y pedagogos) y la prensa, que se generalizó en el tránsito entre los siglos XIX al XX. Teniendo en cuenta la precaria situación en que se encontraban ciertos sectores de esta infancia, se creía que podían fácilmente traspasar el umbral de la pobreza y la marginalidad para convertirse en delincuentes. ${ }^{6}$

instituciones de corrección Buenos Aires, 1890-1930, Tesis doctoral, Universidad de Buenos Aires, 2014.

5. El Orden, Azul, “Los niños en la calle. Una mala costumbre", 03/02/1914.

6. De hecho fueron los sectores intelectuales y políticos preocupados por la cuestión obrera los que primero repararon en la situación de la infancia. Ver SURIANO,
Si bien los pueblos aquí estudiados no tenían entonces las dimensiones de ciudades como Buenos Aires o Rosario, que fueron blanco de estas preocupaciones (y han sido también objeto de la mayor parte de los estudios al respecto), el problema de la mendicidad infantil y la vagancia callejera fue puesto sobre el tapete insistentemente por la prensa local. ${ }^{7}$ Con el nuevo siglo y el aumento de

Juan, "El trabajo infantil...", Op. Cit. y AVERSA, María Marta, "Infancia abandonada y delincuente...", Op. Cit.

7. La historiografía sobre la infancia es un campo prolíico. Un estudio insoslayable sobre los comienzos de las políticas sociales encaradas en épocas tempranas en el Río de la Plata es el de MORENO, José Luis (compilador) La politica social antes de la política social (Caridad, beneficencia y politica social en Buenos Aires siglos XVII a XX), Trama/Prometeo, Buenos Aires, 2000. También CIAFARDO, Eduardo, Los niños en la ciudad de Buenos Aires (1890-1910), CEAL, Buenos Aires, 1992. La ciudad de Rosario ha sido objeto de estudios relevantes entre los que mencionamos: BONAUDO, Marta, "Cuando las tuteladas tutelan y participan. La Sociedad Damas de Caridad (1869-1894)", en Signos Históricos, México, 2006, №15, pp. 70-97; DALLA CORTE, Gabriela y PIACENZA, Paola, A las puertas del Hogar. Madres, niños y damas de caridad en el Hogar del Huérfano de Rosario (1870-1920), Prohistoria, Rosario, 2006 y ULLOQUE, Marcelo, Asilar a las niñas. La construcción de un espacio de género. (Rosario, 1935-1955), Prohistoria, Rosario, 2011. En los últimos años, nuevos aportes han venido a enriquecer con nuevas perspectivas de análisis el campo. Entre ellos mencionamos entre otros GUY, Donna, Las mujeres y la construcción del Estado de Bienestar. Caridad y creación de derechos en Argentina, Prometeo, Buenos Aires, 2011; AVERSA, María Marta, "Infancia abandonada y delincuente...", Op. Cit.; ZAPIOLA, Carolina, La invención del menor..., Op. Cit. y ZAPIOLA, Carolina, Un lugar para los menores..., Op. Cit. Los trabajos que remiten a la infancia en la provincia de Buenos Aires son escasos. Desde otras perspectivas e intereses, se refieren a ella STAGNO, Leandro, Una infancia aparte. La minoridad en la provincia de Buenos Aires (1930-1943), Libros Libres, Buenos Aires, 2010; DELGADO, Susana, La gracia disciplinada. Detrás de los muros del Asilo Unzué, Mar del Plata, 1912-1955, Biblos, Buenos Aires, 2011; BRACAMONTE, Lucía, "Mujeres benefactoras en el sudeste bonaerense argentino: el caso del Patronato de la Infancia de Bahía Blanca, 1906- 
población que experimentaron estos espacios, la visibilidad de niños en las calles se tornó insoslayable. ${ }^{8}$ Conforme crecían Azul y Tandil, aumentó también la referencia a los niños que recorrían las calles haciendo alguna travesura, en busca de esparcimiento mientras sus padres trabajaban evadiendo así sus controles, evitando la asistencia a clases y en ciertos casos para ejercer la mendicidad (cuando no algún trabajo callejero) que los sustentase ante la ausencia de familia, o por la necesidad de colaborar con ésta.

Con la diatriba de la prensa, confluyeron las preocupaciones de sectores locales que incluyeron a benefactoras, autoridades y a la comunidad en su conjunto, quienes pusieron en marcha diversas estrategias para socorrer a la infancia que consideraban en peligro. $\mathrm{Si}$ no fueron las únicas, se destacó en magnitud y perdurabilidad en el tiempo la obra de las Damas de Caridad del Sagrado Corazón de Jesús que en ambos pueblos y sin mantener vinculación entre sí, fundaron casi en simultáneo sendos asilos para huérfanas, con el objetivo de dar albergue y educación a niñas que habían perdido a sus padres (o a alguno de ellos) así como también, a aquellas que aun teniendo familia necesitaban de estas instituciones por no poder sus progenitores o allegados hacerse cargo. ${ }^{9}$ Con cierto retraso en

\section{1”, Historelo, Medellín, 2012, № 4, pp. 48-84.}

8. De los datos que se desprenden del Segundo y Tercer Censo Nacional respectivamente, se evidencia que el crecimiento de población fue de importante magnitud en la provincia de Buenos Aires en su totalidad, con un destacado impacto en el aumento de la población urbana, que afectó también al espacio de análisis. De acuerdo al Censo Nacional de Población de 1895, Azul tenía un total de habitantes entre población urbana y rural de 23.115 personas, y Tandil 14.982. Para 1914, las cifras habían aumentado notablemente, contándose los habitantes de Azul en 32.103 y los de Tandil en 34.061.

9. El Asilo Sagrado Corazón de Azul se fundó en 1896 y el de Tandil en 1897. Otras instituciones dedicadas a relación a las iniciativas en favor de las niñas y pasada la primera década del siglo XX, en Azul desarrollaron también una labor destacada por los niños de sexo masculino las señoras de la Pía Unión de San Antonio.

\section{Por las calles de la ciudad: la prensa mira a los niños y escribe}

Tras el comienzo del nuevo siglo, la prensa local incrementó un viejo reclamo que sostuvo a lo largo de las primeras décadas del mismo: aquel que sostenía que los chicos en edad escolar, solían cambiar la seguridad de las aulas por la diversión de las calles, ${ }^{10}$ especialmente a

la protección de la infancia fueron las Congregaciones de las Hijas de María que existían en ambos pueblos y sostenían talleres de costura en los que confeccionaban ropa para los más necesitados. En Azul se destacó la Sociedad Protectora de Niños Pobres, fundada en 1898 por un grupo de señoras entre las cuales había maestras y directoras de los establecimientos escolares, con la intención de arbitrar los recursos para repartir ropa y calzado a los niños carecientes que concurrían a las escuelas del partido y que solían argumentar esta carencia para justificar su ausencia de las aulas. Similares objetivos se planteó en Tandil la Sociedad Belgrano Amigos de la Educación, donde tuvo protagonismo el accionar de Catalina Miguens, maestra de reconocida actuación en la localidad.

10. La problemática de los niños y su presencia en las calles ha sido profusamente estudiada para Buenos Aires. Ver entre otros ZAPIOLA, Carolina, "Niños en las calles: imágenes literarias y representaciones oficiales en la Argentina del Centenario", en GAYOL, Sandra y MADERO, Marta (editoras) Formas de Historia Cultural, Universidad Nacional de General SarmientoPrometeo, Buenos Aires, 2007, pp. 305-332 y RÍOS, Julio César y TALAK, Ana María, "La niñez en los espacios urbanos”, en DEVOTO, Fernando y MADERO, Marta (directores) Historia de la Vida Privada en la Argentina, T.2, Taurus, Buenos Aires, 2000, pp. 139- 161. Un trabajo ya clásico pero de referencia obligada es el de CIAFARDO, Eduardo, Los niños en la ciudad de Buenos Aires..., Op. Cit. 
la hora de la siesta cuando los desprevenidos vecinos que descasaban de sus tareas cotidianas, no podían atrapar a tiempo a los niños y jovencitos que aprovechaban la quietud de la tarde para saltar cercados y “....apoderarse de la fruta de los pacíficos vecinos ...", o como decía años más tarde El Eco de Tandil, tocar timbres y golpear puertas para salir corriendo luego de la salida de la escuela. ${ }^{11}$ Otras transgresiones reiteradas a lo largo del periodo como la presencia de menores en cafés, bares, billares y hasta casas de tolerancia, revestían mayor gravedad por cuanto se creía que estos lugares ponían en riesgo su moralidad. ${ }^{12}$ En estos casos, además de reclamar la atención de los padres para que tomaran las medidas del caso, se insistía en la necesidad de complementar esta intervención con la presencia policial que

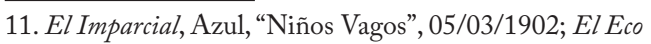
de Tandil, Tandil, "Menores traviezos [sic]", 14/9/1911.

En este artículo, sin desconocer las diferencias que encerraban las categorías niño y menor, son usadas indistintamente, tal como se presentan en las fuentes consultadas. Me centro mayoritariamente en los pertenecientes a los sectores populares cuya situación es aquella que se ve reflejada en la documentación analizada $\mathrm{y}$ refiero a menores en tanto que menores de edad. De acuerdo con lo establecido en el Código Civil vigente en el periodo de estudio, se consideraban menores de edad $\underline{a}$ los individuos de uno y otro sexo que no llegasen a 22 años cumplidos. Los menores de 14 años, por su parte, eran considerados impúberes. Código Civil, Libro I, Sección I, Título IX: De los menores, Arts. $1^{\circ}$ y $2^{\circ} \ldots$ Op. Cit., p. 51. Por niños o niñas aquí entiendo aquellos que no superaban los 14 años y como jovencitos a aquellos comprendidos entre esta edad y la mayoría de edad que regía en la época. Finalmente, no se trata de actores sociales que puedan considerarse delincuentes, sino apenas transgresores de ciertas normas de moralidad y urbanidad en construcción así como huérfanos y abandonados que ejercían la mendicidad y algunos trabajos callejeros.

12. El Imparcial, Azul, "Jóvenes aprovechados", 11/05/1902; El Eco de Tandil, Tandil, "Menores en los billares", 19/02/1911 y El Ciudadano, Azul, "La vagancia", 22/09/1915. pusiera fin a estos comportamientos. ${ }^{13}$

Con el pasar de los años el reclamo persistió. Bien decía La Democracia que “...nos hemos ocupado muchas veces del mal que entraña la presencia de menores en lugares que significan un paso inicial en el camino de la corrupción”, de allí, que creía imprescindible llamar a las autoridades para que tomaran a su cargo la "...represión de su admisión en locales determinados" que ponían en riesgo "...la moral de la infancia, de la que tienen tan pocas nociones la generalidad de los padres de familia”. ${ }^{14}$

El Imparcial había utilizado términos más duros años antes para aludir a actividades que no solo podían poner en peligro la moralidad de los niños y jóvenes que frecuentaban lugares no convenientes como los antes mencionados, sino también afectaba a los vecinos, en un grado mayor que robando frutas o tocando timbres. Así, en 1910, este órgano de prensa no dudaba en responsabilizar a estos grupos, a los que denominaba "lacra social", de pintar paredes, lo que era, decía, "...producto de muchachos vagos que pululan por las calles de la ciudad...". Más aún, se trataba según afirmaba de “... letreros en todas las paredes que ofenden el pudor de las personas mayores y mucho más de nuestras niñas...”. Nuevamente, el entorno geográfico de los cafés y los cinematógrafos, era citado como el espacio donde “...suelen campar [sic] libremente estos pequeños vagos dando un triste y bochornoso espectáculo...”. ${ }^{15}$ Más allá de algún reclamo a los padres para

13. El Comercial, Azul, "Los menores”, 11/6/1906.

14. La Democracia, Azul, “Los menores”, 18/09/1913.

Cabe señalar que represión fue el término más usado por la prensa consultada para sugerir las actitudes que debían tomar las autoridades. Entre otros ver El Imparcial, Azul: "Muchachos atrevidos. necesidad de represión, 01/02/1902; “Jóvenes...”, Op. Cit.; “Para reprimir la vagancia infantil, 14/07/1910.

15. El Imparcial, Azul, “Lacra social”, 15/07/1910. 
que tomaran cartas en el asunto (aunque solían reconocer que tenían poca confianza en que así lo hicieran dada su habitual desaprensión), estos medios insistían en depositar las soluciones en las autoridades, principalmente en el comisario y sus ayudantes quienes, decían, debían emprender una tarea moralizadora para “...cortar de raíz esta vergüenza, este cáncer social de los muchachos sueltos... en pro de nuestra cultura y de nuestra moral social...". ${ }^{16}$

A pesar de la voluntad homogeneizadora del discurso de la prensa que insistía en englobar bajo el mote de vagos a los menores de edad que transitaban las calles de la ciudad, las realidades y experiencias de estos grupos de chicos debieron ser bien diferentes. Hacer alguna travesura (como robar fruta), no implicaba hacerlo por hambre, como podría ser la causa que llevaba a muchos otros a mendigar por las calles. Evadir controles paternos y faltar a clases, no conllevaba necesariamente la carencia de familia ni pertenecer a una con padres desinteresados por la moral de sus hijos. Esto tampoco va de suyo si se trataba de niños y jovencitos que querían experimentar la transgresión de entrar en un billar o hasta en una casa de tolerancia. Más allá de las realidades y experiencias de cada uno, el objetivo de la prensa no era diferenciarlos sino más bien estereotipar una imagen. Antes que referir por ejemplo a las diferencias sociales que podían explicar las causas de su presencia en la vía pública, los medios de prensa subrayaron lo que consideraban conductas inmorales para evitar así que el mal comportamiento se transformase en hábitos nocivos para los futuros ciudadanos, trabajadores $y$ madres en que debían convertirse quienes eran protagonistas de estos comentarios. ${ }^{17}$

16. Ibídem. Ver también El Eco de Tandil, Tandil, "Vagabundeando", El Eco de Tandil, Tandil, 23/03/1911;

"Vagos y vaguitos", El Eco de Tandil, Tandil, 28/04/1912 e "Infancia vagabunda", 13/09/1914, entre otros.

17. Cabe señalar también que las menciones a la
Sin embargo, otros periódicos transmitieron comentarios detrás de las cuales se cuelan nociones que permiten introducir ciertos matices a la hora de reflejar las ideas generales en torno a la manera en que era percibido el problema de la infancia y sus posibles soluciones. Si como señalamos la prédica generalizada involucraba a niños vagos varones antes que a mendigos y abandonados o a niñas, y el remedio se creía que estaba en manos de padres más severos o en las autoridades y sus medidas represivas, El Pueblo de Azul reparaba más en la situación de los niños de sexo masculino que deambulaban por las calles por no disponer (como sí tenían las niñas) de un lugar donde alojarse. De allí que en 1904, señalaba que “...en el Azul tenemos un asilo de huérfanas del sexo femenino pero no hay quien recoja los niños varones... En este pueblo no hay quien recoja un niño. En bandada, harapientos, sucios y desgreñados, en la escuela del vicio recorren las calles centenares de criaturas...". ${ }^{18} \mathrm{Si}$ eran, tal como decía, centenares los chicos que andaban por las calles, no podemos precisarlo. En cambio es factible inferir que más allá de la cantidad, una parte de la sociedad de Azul también percibió que un sector de la infancia de la ciudad requería de otro modo de ayuda y contención. De hecho por esos mismos años otra comisión de beneficencia católica, la mencionada Pía Unión de San Antonio (que se había organizado el 13 de junio de 1899 con el objeto de socorrer con alimentos y ropa a los pobres de la localidad), comenzó a barajar la

presencia en las calles se relacionaban mayoritariamente con niños de sexo masculino, mientras que cuando se hablaba de niñas, se las reflejaba mendigando, aunque se hicieran también referencias esporádicas a su vagancia o deambular callejero. El Imparcial, Azul, "Niños vagos", 8/7/1902; "La cuestión asilos”, 25/10/1906. Para Tandil: El Eco de Tandil, Tandil, "Pequeñas limosneras", 07/08/1910 y El Eco de Tandil, Tandil, "Mal social”, 21/08/1913, entre otros.

18. El Pueblo, Azul, “Asilo de huérfanos”, 11/03/1904. 
idea de fundar un asilo para niños que en 1911 se transformó en el Asilo San Antonio.

Este medio de prensa manifestó diferencias a la hora de pensar la salida a un problema que era compartido por varios sectores de la localidad: el asilo como espacio de contención y formación, debía sumarse como complemento a las acciones meramente represivas. Los otros diarios analizados mostraron menos una preocupación por la infancia como objeto de derechos, que una más palpable por el orden social que explica la insistencia en reclamos de acciones por parte de autoridades que debían intervenir para evitar que estas ciudades en desarrollo se vieran frente a una cara que no deseaban ver, la de los muchachos vagos. El Pueblo en cambio, advertía que además de muchachos vagos y la necesidad de moralizar sus costumbres, había un sector de la infancia sobre el que debían desplegarse otras estrategias de acción, específicamente decía, debían encontrar un lugar donde cobijar su abandono. Señalaba así que "...es necesario recoger esos huérfanos, darles albergue, alimentarlos, enseñarles a leer y a trabajar...”. ${ }^{19}$ De ahí que, desde sus páginas, se dedicó a apoyar con ahínco la iniciativa de la Pía Unión de San Antonio. A pesar de que como dejó claro era una publicación que no simpatizaba con las obras de carácter católico, reconocía la importancia del proyecto de esta asociación para lo cual llamaba a las "familias pudientes" de la localidad a ayudar a "...las distinguidas damas azuleñas que patrocinan la idea apuntada y que de llevarse a la práctica tendrá consecuencias benéficas para esta población". ${ }^{20}$ En síntesis y habiendo pasado varios años desde la fundación del asilo de niñas, un sector de la comunidad de Azul percibió que la subsistencia del problema de la mendicidad y el vagabundeo infantil, si en algunos casos tenía la causa en padres poco

19. El Pueblo, Azul, “Niños vagos”, 19/10/1904.

20. El Pueblo, Azul, “Asilo para niños”, 19/08/1904. severos y desaprensivos o demasiado ocupados para reparar en la acciones de sus hijos durante su tiempo libre, entendieron también que esta persistencia no se debía al fracaso del modelo asistencial aplicado a las niñas sino a su insuficiencia: debían extender su ayuda a los niños de sexo masculino, en una obra que complementara la que se encontraba en pleno funcionamiento. Veamos ahora cómo se articularon esas obras.

\section{Las benefactoras en acción: prácticas hacia la infancia.}

Al margen de los discursos en pro de las acciones a seguir para solucionar los problemas que la prensa señalaba, en los espacios estudiados a las puertas del siglo XX, un conjunto de señoras se pusieron manos a la obra para dar contención y amparo a las niñas y jovencitas que carecían de un cuidado familiar adecuado. En virtud de lo que se consideraba una necesidad urgente, gestaron los asilos para niñas huérfanas que comisiones de beneficencia de similares características e igual nombre pero como adelanté, sin vinculación concreta, establecieron en Azul y Tandil en los años finales del siglo XIX.

La Sociedad Damas de Caridad del Sagrado Corazón de Jesús se fundó en Azul en 1886 y se abocó desde entonces no solo a difundir la doctrina del Sagrado Corazón, ${ }^{21}$ sino también

21. La devoción al Sagrado Corazón de Jesús se constituyó en un elemento central de la pastoral de la iglesia durante la segunda mitad del siglo XIX. En el contexto de enunciación de la bula papal Rerum Novarum de 1891 por medio de la cual la Santa Sede promovió un reposicionamiento de la iglesia católica en la sociedad y en su relación con los Estados liberales, subrayaba la función social de la Iglesia. Con estos postulados floreció el asociacionismo católico en América Latina mediante la difusión de agrupaciones no ya procedentes del catolicismo de la península ibérica como 
a brindar ayuda a los menesterosos del pueblo, a aquéllos enfermos, ancianos, madres solas, viudas, niños y niñas que requerían de cierto amparo, principalmente a través del reparto de ropa y comida a la salida de la misa o atendiendo situaciones particulares que llegaban a sus oídos a través de alguna socia, del párroco o de la misma prensa. ${ }^{22}$

En la década del ' 90 , más precisamente hacia 1894, aumentó considerablemente el número

en el periodo colonial, sino del catolicismo francés. Así se fundaron las Conferencias de San Vicente de Paul, el Apostolado de la Oración o las Congregaciones Marianas. En este contexto, se impulsaron prácticas devocionales centradas en la vivencia de los sacramentos y en la dimensión más afectiva antes que racional, que apuntaba a un Cristo misericordioso. Según plantea Cynthia Folquer, "La devoción al Sagrado Corazón adquirió, durante el siglo XIX, rasgos contrarrevolucionarios...", al ser asumida por los sectores mas integristas y reaccionarios del catolicismo en oposición al "frío racionalismo" decimonónico: “... La devoción al Sagrado Corazón se presentó en clara oposición a la modernidad triunfante. Ante el dominio del racionalismo proponía una fe nacida del corazón y la misericordia”. FOLQUER, Cynthia, Viajeras hacia el fondo del alma. Sociabilidad, politica y religiosidad en las Dominicas de Tucumán, Argentina, 1886-1911, Tesis doctoral, Universidad de Barcelona, 2012, pp. 57-58.

22. Con cierta frecuencia convocaron a la comunidad y repartieron pan y dinero a los pobres fuera de la Iglesia al término de la misa como lo reflejaron en sus actas: Archivo Sagrado Corazón de Jesús de Azul (ASCJA), Actas, 01/07/1894, folio 107; 10/02/1895, folio 125. En otras oportunidades visitaron a los socorridos en sus casas. En la reunión de Junio de 1894, se distribuyó entre las socias una nómina de pobres a los que debían visitar: ASCJA, Actas, 13/06/1894, folio 111. También la prensa reflejó esos repartos. Entre otros El Imparcial, Azul, "La caridad en el Azul", 14/06/1894. Sobre reclamos que llegaron a oídos de las señoras de la comisión que fueron difundidos por la prensa ver El Imparcial, Azul, “Pobres”, 10/06/1894 y “Caridad”, 01/11/1894. Sobre ayuda prestada a través de una socia que transmitió una situación particular ver El Imparcial, Azul, "Caridad", 10/02/1895. de socias, ${ }^{23}$ así como las expectativas. Esto se vio reflejado en la intención de formar un asilo para huérfanas, tal como manifestaron las benefactoras de Azul en 1896, lo cual se concretó, finalmente, en ese mismo año. ${ }^{24}$ Luego de instalar el asilo, éste pasó a ocupar, de lleno, el tiempo y los recursos de las Damas de Caridad azuleñas que se abocaron casi por completo a la contención, alimentación, alojamiento y educación de las niñas huérfanas y abandonadas que recogían. ${ }^{25}$

En el caso de Tandil, si bien las Damas de Caridad se habían organizado en el año 1888 y tenían modalidades de ayuda específicas similares a sus vecinas de Azul, entre sus primeras acciones de envergadura se contó la fundación de un Hospital de Caridad, que funcionó durante varios años. Como ellas sostenían “...es grave, urgente y perentoria la necesidad de erección de un hospital de caridad que en todo llenara las necesidades de su clase reclamadas y apreciadas...". ${ }^{26}$ Durante

23. De acuerdo a lo que ponían de manifiesto las Damas de Caridad de Azul en su Libro de Actas para el año 1892, contaban con 63 Socias Bienhechoras. En 1894, el número de Socias Bienhechoras había trepado a más de 80 miembros.

24. ASCJA, Actas, 08/03/1896, folio 136.

25. Luego de fundado el Asilo, casi mayoritariamente se concentraron en su sostenimiento aunque algunas veces hicieron excepciones y socorrieron pobres: ASCJA, Actas, 03/06/1897, folio 23 y El Comercial, Azul, "La Caridad", 07/06/1906.

26. Si bien Tandil contaba por entonces con el denominado Asilo San Juan, hospital sostenido por la logia masónica local, al parecer y según la prensa consignó, era necesaria la instalación de otro que funcionase con mayor rigurosidad. El Eco de Tandil, Tandil, "Sociedad Damas de Caridad", 06/06/1888. No es posible desconocer que en esta coyuntura existieron una serie de rivalidades entre el poder municipal constituido, la logia masónica y las organizaciones católicas. Al respecto me he referido con detalle en DE PAZ TRUEBA, Yolanda, Mujeres y esfera pública: la campaña bonaerense entre 1880 y 1910, Prohistoria 
años funcionaron en simultáneo el hospital masónico y el de las Damas de Caridad. Pero hacia 1894, las señoras de la Sociedad registraron por primera vez en sus actas su interés por los niños pobres. A tono con esta preocupación, en 1897 decidieron transformar el Hospital de Caridad en asilo de huérfanas, por considerar que representaría mayores beneficios. ${ }^{27} \mathrm{El}$ asilo fue inaugurado en agosto de $1897^{28}$ y desde entonces no dejó de crecer si se tiene en cuenta el movimiento de niñas que ingresaron y se educaron en el asilo, así como por las constantes reformas y ampliaciones efectuadas en el edificio particularmente a partir de 1900, lo que da cuenta de la necesidad de espacios nuevos para una población asilar en aumento. ${ }^{29}$

\section{E1 Asilo San Antonio: promesa de cambios}

En el caso de los infantes varones, aunque la prensa de ambos pueblos abundaba en discursos acerca de su presencia en las calles y la necesidad de contención y/ o represión, no encontramos en Tandil referencia a la intención de acompañar sus acciones con otras similares por los niños como sí sucedió en Azul. ${ }^{30}$

Ediciones, Rosario, 2010 y DE PAZ TRUEBA, Yolanda, "Masonería y Sociabilidad en el centro y sur de la campaña bonaerense. Fines del siglo XIX principios del XX”, en Revista Probistoria (versión on line), Rosario, 2011, No 16. Disponible en <http://ref.scielo.org/ zg5g68>

27. Archivo del Asilo Sagrado Corazón de Jesús de Tandil (ASCJT), Actas, 18/03/1897, folio 103. Ver también Actas, 09/03/1897, folio 102.

28. ASCJT, Actas, 02/08/1897, folio 107.

29. ASCJT, Actas, 24/10/1897, folio 111.

30. Si bien El Eco de Tandil consignó en 1897 que "En una de las últimas sesiones de la comisión directiva [de
Cuando recién comenzaba el siglo XX se difundió allí la idea de fundar un asilo de niños de sexo masculino de la mano de las señoras de la Pía Unión de San Antonio quienes en marzo de 1904 registraron en sus actas que “...manifestó el señor director [párroco César Cáneva] la conveniencia de que la Sociedad Pía Unión de San Antonio, comenzara a preocuparse de la necesidad de fundar un asilo de niños...". 31

De inmediato las voces de aquellos sectores azuleños que representaban lo que ellos mismos denominaban "liberalismo", esto es, el laicismo en cualquier institución que tuviera por fin la formación de los niños y niñas, se alzaron en contra del proyecto. Todo indica que si bien esta idea se hizo explícita recién en 1904, el rumor circulaba por el pueblo antes, dado que El Imparcial se opuso con anterioridad al nuevo siglo a la fundación de un nuevo asilo dado su carácter religioso. Como decía, “...hemos combatido y combatiremos la fundación de un asilo de huérfanos, no ciertamente porque un establecimiento de esta índole sea inútil o de poco mérito, sino porque en los momentos actuales sería extemporáneo y superfluo". Dada la necesidad de brindar educación a los huérfanos y ante la supuesta imposibilidad de encontrar maestros, afirmaba que “...traería como consecuencia lo que debemos evitar a toda costa: que se introduzca en la instrucción pública la enseñanza religiosa sustituyendo la laica... ${ }^{32}$ Sin embargo y más allá del sombrío

las Damas de Caridad] se resolvió recibir también en el Asilo de Huérfanas niños varones desde la edad de 4 años a 9...", en los años estudiados esta medida no se llevó finalmente a cabo. El Eco de Tandil, Tandil, "La Sociedad Damas de Caridad", 02/05/1897.

31. Asilo San Antonio (ASA), Actas, Acta No 9, 17/03/1904, folios 7 y 8.

32. El Imparcial, Azul, "Asilo de huérfanos. Proyecto que quedará en la nada”, 11/08/1899. Cursiva en el original. En 1906 cuando el proyecto ya tenía una forma más definida y las señoras de la comisión procuraban 
pronóstico que planteaba en esta nota, El Imparcial permite inferir que el proyecto avanzaba, al señalar años después que “...el cura de la localidad tiene el decidido propósito de fundar o hacer fundar otra cárcel, decimos, otro asilo para huérfanos". ${ }^{33}$

Como señalé, fue recién en 1904 cuando en las Actas de la Pía Unión se manifestó la intención y por esos años también El Imparcial volvió a hacerse eco de estos propósitos, pero el tono beligerante pareció suavizarse, y señalaba que “...la necesidad de crear una institución de esta naturaleza es imperiosamente sentida en Azul y la fundación de un nuevo asilo vendría a llenar un vacío...". Si bien se mantuvo cauto al no saber la naturaleza que tendría el mismo (aunque decía creer que sería similar al de niñas existente, es decir coordinado por una congregación religiosa), ${ }^{34}$ insistía en que lo más provechoso sería fundar una escuela de artes y oficios “...recogiendo un grupo determinado de huérfanos para convertirlos en artesanos que luego devolvieran a la sociedad para ser miembros útiles a ella". ${ }^{35}$

La cuestión de la necesidad de que los hijos de padres trabajadores fueran educados en

encontrar un terreno donde instalar la institución, $E l$ Comercial decía que aplaudirían con gusto la idea si realmente estuvieran convencidos de que se tratara de algo en beneficio de la infancia, pero lo dudaba ya que según sostenía, lo que comenzaba con el pretexto de ser un asilo terminaba en una escuela religiosa. El Comercial, Azul, “Los menores”, 11/06/1906.

33. El Imparcial, Azul, "Asilo de huérfanas. Los liberales de capa caída”, 05/09/1901.

34. En Azul las hermanas de la Congregación de las Hijas del Divino Salvador estuvieron a cargo de la administración interna y formación de las niñas del asilo durante los primeros diez años de vida del mismo. Desde 1906, se hizo cargo de sus tareas la Congregación de la Inmaculada Concepción.

35. El Imparcial, Azul, "Fundación de un nuevo asilo", 03/09/1904. el trabajo como herramienta moralizadora $\mathrm{y}$ formadora para el futuro, fue parte de un discurso generalizado en el periodo. Como afirmaba Alberto Meyer Arana, el aprendizaje práctico debía realizarse antes de que el menor saliera a trabajar. ${ }^{36}$ Esa formación debía ser especialmente de carácter agrícola, ya que como sostenía “...iniciar al protegido en las faenas rurales, es no solo velar por su prosperidad sino propender al engrandecimiento de la patria...". Tal era así que recomendaba sustituir los asilos urbanos por colonias agrícolas y para aquéllos que tenían familia “...reservamos los externados de oficios...”. ${ }^{37}$

Al margen de este reconocimiento de la necesidad de instruir a los niños pobres en el trabajo, fueron muchos los legisladores (entre ellos predominantemente socialistas), médicos, pedagogos, que a fines del siglo XIX abogaron por la regulación del trabajo infantil de cara a evitar la explotación a la que estaban convencidos se veían sometidos miles de niños. Sin embargo, en ningún momento se pensó en suprimirlo completamente. ${ }^{38}$ Muy por el contario, se creía en la posibilidad de regeneración y preparación para el futuro que este encerraba, en especial si se trataba

36. Profesional comprometido con la cuestión de la infancia quien sostuvo muchas de sus ideas como secretario del Patronato de la Infancia de Buenos Aires. En su discurso no sólo estaban presentes los huérfanos, sino aquellos niños pobres que teniendo padres, especialmente entre diez y doce años (una vez terminada la educación elemental), debían adquirir habilidades prácticas que los preparara para la vida laboral, que según afirmaba, en el caso de los niños de los sectores populares solía comenzar alrededor de los 14 años. MEYER ARANA, Alberto, Por el niño pobre, edición de autor, Buenos Aires, 1904, p.5-6.

37. Ibídem.

38. ZAPIOLA, Carolina, "Los niños entre la escuela, el taller y la calle (o los límites de la obligatoriedad escolar)". Buenos Aires, 1884-1915", en Cadernos de Pesquisa, Fundação Carlos Chagas, Sao Paulo, 2009. 
de los hijos de los sectores populares, grupo social considerado más problemático. ${ }^{39}$ Como sostiene Zapiola, la asistencia de éstos al taller se vislumbraba como un modo de evitar el ocio y la vagancia, lo que devino en la aceptación de cierta regulación del trabajo infantil, así como en la limitación en la práctica de la obligatoriedad escolar que la ley mandaba. ${ }^{40}$

La legislación (e incluso muchos discursos), reposaban sin embargo, en la búsqueda de una reglamentación de aquellos que trabajaban en talleres e industrias, dejando en un segundo plano la situación de los que lo hacían en trabajos domiciliarios, callejeros, en ocupaciones agrícolas o en tareas domésticas. El Asilo San Antonio y los del Sagrado Corazón estaban pensados para una población infantil y juvenil que no estaba compuesta por delincuentes por lo cual en estos casos, el trabajo desempeñaba un carácter preventivo antes que correctivo. ${ }^{41}$

39. La idea del trabajo como regenerador y formador de los hijos de los trabajadores, es propio de un contexto en el que cambió la idea de castigo. Al respecto ver: CAIMARI, Lila, "Castigar civilizadamente. Rasgos de la modernización punitiva en la Argentina (18271930)", en GAYOL, Sandra y KESSLER, Gabriel (compiladores) Violencias, delitos y justicias en la Argentina, Universidad Nacional de General Sarmiento/Manantial, Buenos Aires, 2001. Para el caso de México, un trabajo interesante sobre el carácter regenerador del trabajo es el de SOSENSKY, Susana, "Un remedio contra la delincuencia: el trabajo infantil en las instituciones de encierro de la ciudad de México durante la posrevolución", en Asclepio. Revista de historia de la medicina y de la ciencia, Madrid, 2008, № 2, pp. 95-118.

40. ZAPIOLA, Carolina, La invención del menor..., Op. Cit. y de la misma autora "Los niños entre la escuela, el taller y la calle...” Op. Cit.

41. Sobre la cuestión del trabajo como un instrumento formativo y preventivo para las niñas de los sectores populares nos hemos referido en DE PAZ TRUEBA, Yolanda, "Política social católica: una forma de intervención pública en el ámbito privado de la familia. La campaña centro y sur bonaerense a principios del siglo XX”, ponencia presentada en Jornadas Arreglos familiares,
Si las señoras de la comisión, tenían en mente la idea de instalar en el Asilo San Antonio talleres de artes y oficios, acorde con las ideas del momento en relación a la educación de los niños de las clases trabajadoras desde los comienzos del proyecto, no lo transmitieron en sus actas. No obstante, ese fue el camino emprendido al poco tiempo de haber comenzado a definir los contornos de la futura institución. Así, al momento de su inauguración el $1^{\circ}$ de octubre de 1911, el establecimiento ocupaba el terreno elegido que tenía 100 metros de largo por 40 metros de fondo y que contaba con dormitorios, aulas, comedores y, claro, los lugares reservados para los talleres de zapatería y sastrería, a los que en 1915 se añadió el de imprenta y en 1917 el de encuadernación. ${ }^{42}$

En 1907, las señoras de la comisión lograron contra toda crítica, pronósticos negativos y adversidades propias de un proyecto de la magnitud como el encarado, colocar la piedra fundamental. A pesar de que como comentaba El Imparcial, ese día el clima no acompañó a los presentes mostrándose "desapacible", la ceremonia, que contó con la presencia de Monseñor Alberti, fue "lucida". ${ }^{43}$

Y ya en este momento, el tono de la prensa había variado considerablemente, al señalar que se trataba sobre todo de una escuela la que funcionaría en el asilo que debía ponerse “... bajo la protección del vecindario caritativo y generoso... pues venía a llenar una necesidad cada día mas sentida en esta población”. ${ }^{44}$

A pesar de las posturas adversas de algunos género y sexualidad, CiSoC, FCH UNICEN, Tandil, 2014.

42. ASA, Actas, Acta № 27, 18/09/1906, folio 21 y El Tiempo, "Del Colegio Asilo San Antonio al Colegio Sagrada Familia de Azul”, 02/06/2007.

43. El Imparcial, Azul, "La ceremonia del domingo", 04/06/1907.

44. El Imparcial, Azul, “El nuevo asilo”, 04/06/1907. 
órganos de prensa en contra de la iniciativa del nuevo asilo, lo cierto es que en cuanto trascendió que éste tendría por objeto la formación de los niños que fueran recogidos allí en oficios que los trasformase en hombres útiles para la sociedad, el tono de estos mismos medios de prensa cambió. Si bien se mantuvieron circunspectos y siempre fueron críticos respecto de la forma en que era ejercida la caridad católica, cierto es que el Asilo San Antonio encarnó un proyecto diferente para una población asilar también distinta: para los varones se pensó en una solución más integral por medio de la cual al dar albergue, educación y formación en hábitos morales y conocimientos básicos de lectoescritura, se sumaron los talleres de artes y oficios para los hijos de padres trabajadores que, no pudiendo atenderlos personalmente, en cambio, sí se preocupaban por el destino de sus hijos. ${ }^{45}$ Como se señalaba “...nuestro obrero progresa, abandona su incuria tradicional y se preocupa por el porvenir de sus hijos. Hoy quiere educación para su prole...”. ${ }^{46}$ Además, debía mitigar la mendicidad que tanto preocupaba ya que, como comentaba, "Aparte de las ventajas que reportará el asilo de niños próximo a inaugurarse, y de las cuales ayer nos ocupamos, tendrá la de suprimir o atenuar bastante la mendicidad infantil..." ${ }^{47}$

45. En otro trabajo he mostrado cómo para las Damas de Caridad que tenían a su cargo los asilos de niñas fue importante la formación de éstas como madres y amas de casa e incluso (aunque a una minoría de ellas), las preparaban para el mercado laboral para insertarse como maestras, antes que como trabajadoras domésticas. Ver DE PAZ TRUEBA, Yolanda, "Educar a las huérfanas: una mirada desde un asilo del sureste de la provincia de Buenos Aires a principios del siglo XX", en Revista Polhis, Buenos Aires, 2014, No 13, pp. 85-98.

46. El Imparcial, Azul, "El nuevo Asilo”, 1/9/1910.

47. El Imparcial, Azul, “El asilo de niños”, 2/9/1910.

\section{Conclusiones}

Antes del nuevo siglo, tanto en Azul como en Tandil, la evidencia de que el abandono de niños y la mendicidad no era un fenómeno nuevo, se hizo más visible. Esta situación había llevado a ciertos sectores benefactores privados de corte católico auxiliados por el estado municipal, a ensayar soluciones para dar contención y amparo a niñas y jovencitas. Sin embargo, como la prensa comentaba en 1906, a pesar de que los asilos eran una solución extendida, no habían solucionado la cuestión de la infancia ya que como afirmaba El Imparcial de Azul, “...existe un asilo de huérfanas y sin embargo todos los días nos encontramos en la calle con niñas de corta edad que imploran el óbolo público...". 48

En las páginas que anteceden, nos preguntamos entonces si esos ensayos habían fracasado en su intento, ya que comentarios de este tenor, fueron habituales en las páginas de la prensa estudiada aun después de haber pasado mucho tiempo tras haberse fundado no solo los Asilos del Sagrado Corazón sino también el Asilo San Antonio. ${ }^{49}$

Sostuvimos que no es factible hablar de fracaso de las soluciones emprendidas. Más

48. El Imparcial, Azul, “La cuestión asilos”, 25/10/1906.

$\mathrm{Si}$ bien no se puede desconocer que detrás de comentarios como los vertidos por El Imparcial y El Comercial de Azul hay una antipatía manifiesta por las obras de carácter religioso, y al aludir a casos de vagabundeo y mendicidad infantil, estaban indirectamente poniendo sobre el tapete la forma inapropiada en la que se ejercía la caridad católica, estas fuentes me permitieron de igual modo el abordaje de una realidad: la de los niños que no tenían padres, o la de los que aun teniéndolos, pasaban largas horas en la calle.

49. Entre otros, El Orden, Azul, "Muchachos vagos", 04/12/1913; El Ciudadano, Azul, "Mendicidad callejera", 16/07/1915 y “La vagancia”, 22/09/1915. 
bien es válido pensar que el desarrollo de la modernización y el aumento de la urbanización de estos espacios, avasalló las capacidades asistenciales privadas que por otra parte fueron las únicas del período y siguieron siéndolo por mucho tiempo.

Más allá de las acciones emprendidas desde las instituciones asilares en pro de resolver la situación de la infancia, la modernidad puso en jaque esas soluciones toda vez que las hacía insuficientes; producto de esa misma modernidad, las calles siguieron albergando a los niños de las familias trabajadoras que no se ajustaron a los modelos requeridos.

Sin embargo, las fuentes abordadas desde una escala local nos han mostrado cómo el discurso y las intenciones de los actores sociales involucrados en la gestión y concreción de los proyectos asistenciales, fue homogéneo en tanto no evaluaron soluciones alternativas a la hora de resolver problemáticas de la infancia de las clases trabajadoras. La sociedad de Azul concibió la necesidad de fundar otro asilo (en este caso para niños de sexo masculino), como forma de atender las demandas de aquellos que así lo requirieran. A pesar de las críticas, en el espacio estudiado la estrategia asilar privada de corte religioso, siguió siendo la única posible.<smiles>CC=[Te]=CC</smiles> 


\section{Bibliografía}

AVERSA, María Marta, "Infancia abandonada y delincuente. De la tutela al patronato público (19101931)”, en LVOVICH, Daniel y SURIANO, Juan (editores) Las politicas sociales en perspectiva histórica. Argentina, 1870-1952, Prometeo - Universidad Nacional de General Sarmiento, Buenos Aires, 2006.

BONAUDO, Marta, "Cuando las tuteladas tutelan y participan. La Sociedad Damas de Caridad (18691894)”, en Signos Históricos, México, 2006, No15, pp. 70-97.

BRACAMONTE, Lucía, "Mujeres benefactoras en el sudeste bonaerense argentino: el caso del Patronato de la Infancia de Bahía Blanca, 1906-1931”, Historelo, Medellín, 2012, No 4, pp. 50-83.

CAIMARI, Lila, "Castigar civilizadamente. Rasgos de la modernización punitiva en la Argentina (18271930)", en GAYOL, Sandra y KESSLER, Gabriel (compiladores) Violencias, delitos y justicias en la Argentina, Universidad Nacional de General Sarmiento/Manantial, Buenos Aires, 2001.

CIAFARDO, Eduardo, Los niños en la ciudad de Buenos Aires (1890-1910), CEAL, Buenos Aires, 1992.

DALLA CORTE, Gabriela y PIACENZA, Paola, A las puertas del Hogar. Madres, niños y damas de caridad en el Hogar del Huérfano de Rosario (1870-1920), Prohistoria, Rosario, 2006.

DELGADO, Susana, La gracia disciplinada. Detrás de los muros del Asilo Unzué, Mar del Plata, 1912-1955, Biblos, Buenos Aires, 2011.

DE PAZ TRUEBA, Yolanda, Mujeres y esfera pública: la campaña bonaerense entre 1880 y 1910, Prohistoria Ediciones, Rosario, 2010.

DE PAZ TRUEBA, Yolanda, "Masonería y Sociabilidad en el centro y sur de la campaña bonaerense. Fines del siglo XIX principios del XX”, en Revista Prohistoria (versión on line), Rosario, 2011, No 16. Disponible en <http://ref.scielo.org/zg5g68>.

DE PAZ TRUEBA, Yolanda, "Política social católica: una forma de intervención pública en el ámbito privado de la familia. La campaña centro y sur bonaerense a principios del siglo XX”, ponencia presentada en Jornadas Arreglos familiares, género y sexualidad, CiSoC, FCH UNICEN, Tandil, 2014.

DE PAZ TRUEBA, Yolanda, "Educar a las huérfanas: una mirada desde un asilo del sureste de la provincia de Buenos Aires a principios del siglo XX”, en Revista Polhis, Buenos Aires, 2014, No 13, pp. 85-98.

FOLQUER, Cynthia, Viajeras hacia el fondo del alma. Sociabilidad, politica y religiosidad en las Dominicas de Tucumán, Argentina, 1886-1911, Tesis doctoral, Universidad de Barcelona, 2012.

GUY, Donna, Las mujeres y la construcción del Estado de Bienestar. Caridad y creación de derechos en Argentina, Prometeo, Buenos Aires, 2011.

MORENO, José Luis (compilador) La politica social antes de la politica social (Caridad, beneficencia y politica social en Buenos Aires siglos XVII a XX), Trama/Prometeo, Buenos Aires, 2000. 
RÍOS, Julio César y TALAK, Ana María, "La niñez en los espacios urbanos", en DEVOTO, Fernando y MADERO, Marta (directores) Historia de la Vida Privada en la Argentina, T. II, Taurus, Buenos Aires, 2000 .

SOSENSKY, Susana, "Un remedio contra la delincuencia: el trabajo infantil en las instituciones de encierro de la ciudad de México durante la posrevolución”, en Asclepio. Revista de historia de la medicina y de la ciencia, Madrid, 2008, № 2, pp. 95-118.

STAGNO, Leandro, Una infancia aparte. La minoridad en la provincia de Buenos Aires (1930-1943), Libros Libres, Buenos Aires, 2010.

SURIANO, Juan, "El trabajo infantil", en TORRADO, Susana (compiladora) Población y bienestar en la Argentina del primero al segundo Centenario. Una historia social del siglo XX. T. II, Edhasa, Buenos Aires, 2007.

ULLOQUE, Marcelo, Asilar a las niñas. La construcción de un espacio de género. (Rosario, 1935-1955), Prohistoria, Rosario, 2011.

ZAPIOLA, Carolina, La invención del menor: representaciones, discursos y politicas de menores en la ciudad de Buenos Aires, 1882-1921, Tesis de Maestría, Universidad Nacional de San Martín, Buenos Aires, 2007.

ZAPIOLA, Carolina, "Niños en las calles: imágenes literarias y representaciones oficiales en la Argentina del Centenario", en GAYOL, Sandra y MADERO, Marta (editoras) Formas de Historia Cultural, Universidad Nacional de General Sarmiento - Prometeo, Buenos Aires, 2007.

ZAPIOLA, Carolina, "Los niños entre la escuela, el taller y la calle (o los límites de la obligatoriedad escolar). Buenos Aires, 1884-1915”, en Cadernos de Pesquisa, Fundação Carlos Chagas, Sao Paulo, 2009, pp. 69-81.

ZAPIOLA, Carolina, Un lugar para los menores. Patronato estatal e instituciones de corrección Buenos Aires, 1890-1930, Tesis doctoral, Universidad de Buenos Aires, 2014. 